\title{
Bioassays for Assessing Jasmonate-Dependent Defenses Triggered by Pathogens, Herbivorous Insects, or Beneficial Rhizobacteria
}

\author{
Saskia C.M. Van Wees, Johan A. Van Pelt, Peter A.H.M. Bakker, \\ and Corné M.J. Pieterse
}

\begin{abstract}
Jasmonates, together with other plant hormones, are important orchestrators of the plant immune system. The different hormone-controlled signaling pathways cross-communicate in an antagonistic or a synergistic manner, providing the plant with a powerful capacity to finely regulate its immune response. Jasmonic acid (JA) signaling is required for plant resistance to harmful organisms, such as necrotrophic pathogens and herbivorous insects. Furthermore, JA signaling is essential in interactions of plants with beneficial microbes that induce systemic resistance to pathogens and insects. The role of JA signaling components in plant immunity can be studied by performing bioassays with different interacting organisms. Determination of the level of resistance and the induction of defense responses in plants with altered JA components, through mutation or ectopic expression, will unveil novel mechanisms of JA signaling. We provide detailed protocols of bioassays with the model plant Arabidopsis thaliana challenged with the pathogens Botrytis cinerea and Pseudomonas syringae, the insect herbivore Pieris rapae, and the beneficial microbe Pseudomonas fluorescens. In addition, we describe pharmacological assays to study the modulation of JA-regulated responses by exogenous application of combinations of hormones, because a simultaneous rise in hormone levels occurs during interaction of plants with other organisms.
\end{abstract}

Key words Arabidopsis thaliana, SA, JA, Plant hormones, Bioassay, ISR, Herbivorous insect, Plant immunity

\section{Introduction}

The use of bioassays to study the effects of treatments on the resistance level of plants against an attacker has been recorded for the first time at the beginning of the twentieth century $[1,2]$. Numerous examples were described in which plants were protected against pathogen infection after pretreatment with (attenuated) pathogens or extracts obtained from pathogens $[1,2]$. In nature, plants encounter a plethora of harmful and beneficial organisms, including 
bacteria, fungi, oomycetes, viruses, nematodes, and insects. Each of these interacting organisms exploits highly specialized features to establish an intimate relationship with its host plant.

The plant responds differently to various types of ingression by interacting organisms through changes in levels of and sensitivity to plant hormones. Plant hormones play an important role in the organization of the immune signaling network that induces defense responses. The hormones jasmonic acid (JA) and salicylic acid (SA) are recognized as major players in plant immune signaling, whereas other hormones have modulating roles in the JA- and SA-controlled responses [3]. JA-regulated defenses triggered by wounding control resistance to insect herbivores [4] and also to pathogens with a necrotrophic lifestyle. These pathogens first kill the cells and then live on the contents [5]. Here, we describe bioassays with Arabidopsis thaliana and the JA-controlled necrotrophic pathogen Botrytis cinerea and the herbivorous insect Pieris rapae. Biotrophic pathogens, such as Hyaloperonospora arabidopsidis, that keep the host cells alive and retrieve nutrients by forming specialized feeding structures (haustoria), are controlled by SA-regulated defense responses [5]. Some plant pathogens display both necrotrophic and biotrophic lifestyles, depending on the stage of their life cycle, and are called hemi-biotrophs. The chapter also provides a description of a bioassay with the hemi-biotrophic bacterial pathogen Pseudomonas syringae.

Beneficial soil-borne microorganisms, such as mycorrhizal fungi and plant growth-promoting rhizobacteria, can cause induced systemic resistance (ISR) in distant plant parts $[6,7]$. During ISR, a mild, but effective, immune response is activated in systemic tissues that in many cases is regulated by JA-dependent signaling pathways. ISR is associated with priming for accelerated JA-dependent defense gene expression rather than with direct activation of defense responses, and is predominantly effective against a broad spectrum of pathogens and insects that are sensitive to JA-controlled defenses [8,9]. In Arabidopsis, ISR triggered by the rhizosphere-colonizing bacterium Pseudomonas fluorescens WCS417 is well studied and bioassays to assess WCS417-ISR are described in this chapter.

In recent years, molecular, genetic, and genomic tools have been used to uncover the complexity of the hormone-regulated induction of the defense signaling network. Besides balancing of the relative abundance of different hormones, intensive interplay between hormone signaling pathways has emerged as an important regulatory mechanism by which the plant is able to tailor its immune response to the type of invader encountered $[10,11]$. For example, resistance of Arabidopsis to P. was shown to depend on activation of SA signaling, and was associated with suppression of JA signaling $[12,13]$. JA-dependent resistance to the necrotrophic fungal pathogen $B$. cinerea was found to be synergized by ethylene, but antagonized by abscisic acid (ABA) [14, 15]; opposite 
effects of ethylene (antagonistic) and ABA (synergistic) on JA-dependent resistance against insect herbivores were reported $[16,17]$. Pharmacological assays in which hormones are applied to the plant have further elucidated some of the molecular mechanisms involved in the communication between different hormone signaling pathways $[3,18-22]$. Modulation of JA signaling by other hormones has been reported to occur by interfering with the function of certain JA signaling components, such as the transcription factor MYC2 in the case of ethylene and ABA, but their exact influence on MYC2 is still not clear [14, 23]. For the antagonistic effect of SA on JA signaling, the JA-regulated transcription factor ORA59 has been suggested as target [20]. Pharmacological assays with combinations of defense-related hormones are described in this chapter.

Despite its unquestioned role in the plant's immunity, many aspects of JA signaling are still unresolved. The use of proper bioassays and pharmacological assays, as described here, will help us to piece the JA puzzle together.

\section{Materials}

\subsection{Equipment}

1. Growth chambers set at $21{ }^{\circ} \mathrm{C}, 70 \%$ relative humidity, and 10-h/14-h day/night regime with a light intensity during the day of $200 \mu \mathrm{E} / \mathrm{m}^{2} / \mathrm{s}$ provided by bulb HPI lamps (Philips, Eindhoven, The Netherlands) or LuxLine plus F58W/840 cool white tube lamps (Havells Sylvania, London, UK).

2. Large autoclave $(50 \mathrm{~L})$ and autoclavable plastic bags $(40 \times 60 \mathrm{~cm})$.

3. Containers $(30-50 \mathrm{~L})$ for mixing water and solutions through soil.

4. Sieved potting soil mixed with river sand $(12: 5 \mathrm{v} / \mathrm{v})$.

5. Small trays (100-500 mL; $4 \mathrm{~cm}$ high) for seedling cultivation.

6. Pots $(60 \mathrm{~mL})$ with holes in the bottom for plant cultivation after the seedling stage.

7. Small 5-cm Petri dishes.

8. Trays (approximately $45 \times 30 \times 8 \mathrm{~cm}$ ) to contain small trays or pots that can be covered with transparent lids to achieve $100 \%$ relative humidity.

9. Tweezers with curved beak tip.

10. Table centrifuge.

11. Spectrophotometer.

12. Incubator set at $22{ }^{\circ} \mathrm{C}, 10$-h day/14-h night, Philips TL-D $36 \mathrm{~W} / 33$ lamps for fungus growth or at $28{ }^{\circ} \mathrm{C}$ for bacterial growth.

13. Hemocytometer. 


\subsection{Buffers, Media, and Solutions}

2.2.1 Arabidopsis thaliana Cultivation

2.2.2 Pseudomonas fluorescens ISR Bioassay

2.2.3 Botrytis cinerea Bioassay
14. Light microscope.

15. Empty pipette tip box.

16. Needleless 1-mL syringe.

17. One-hole puncher (diameter $6 \mathrm{~mm}$ from an office supplier).

18. 96-Deep-well microplate (96-well format boxes containing 12 disposable 8-strip tubes and caps (Greiner Bio-one, Frickenhausen, Germany)).

19. Stainless steel beads (diameter $2.3 \mathrm{~mm}$ ).

20. Orbital shaker at $28^{\circ} \mathrm{C}$.

21. Plate shaker MM301 (Retsch, Haan, Germany) or a regular paint shaker.

22. 8-Channel pipette $(10,20,180 \mu \mathrm{L})$.

23. 96-Well dilution plates $(\geq 200 \mu \mathrm{L})$.

24. Fine paintbrush.

25. A desiccator or other device that can be air-tightly closed.

1. Seeds of Arabidopsis thaliana (L.) Heynh.

2. $0.1 \%(\mathrm{w} / \mathrm{v})$ agar.

3. Half-strength, modified Hoagland nutrient solution: $2 \mathrm{mM}$ $\mathrm{KNO}_{3}, 5 \mathrm{mM} \mathrm{Ca}\left(\mathrm{NO}_{3}\right)_{2}, 1 \mathrm{mM} \mathrm{KH} \mathrm{PO}_{4}, \mathrm{lmM} \mathrm{MgSO}$, trace elements, $\mathrm{pH} \quad 7$ [24], $10 \mu \mathrm{M}$ Fe-ethylenediamine-di[ 0 hydroxyphenylacetic acid] (Sequestreen; Ciba-Geigy, Basel, Switzerland) ( see Note 1).

4. Plant labels.

1. P. fluorescens strain WCS417 [25] or any other biocontrol pseudomonad strain (stocks stored in $25 \%$ glycerol at $\left.-80{ }^{\circ} \mathrm{C}\right)$.

2. King's $B(\mathrm{~KB})$ medium agar [26]: 20 g proteose peptone no. 3 (Difco $^{\mathrm{TM}}$ BD Diagnostics, Franklin Lakes, NJ, USA), $10 \mathrm{~g}$ glycerol, $1.5 \mathrm{~g} \mathrm{MgSO}_{4}, 1.2 \mathrm{~g} \mathrm{KH}_{2} \mathrm{PO}_{4}$ per liter demineralized water supplemented with $13 \mathrm{~g}$ of granulated agar $\left(\mathrm{Difco}^{\mathrm{TM}}\right)$ for the solid medium in Petri dishes (see Note 2).

3. Sterilized $10 \mathrm{mM} \mathrm{MgSO}_{4}$.

1. Pathogen B. cinerea isolate B0510 (stocks stored in $25 \%$ glycerol at $\left.-80{ }^{\circ} \mathrm{C}\right)$.

2. Half-strength potato dextrose broth (PDB; Difco $\left.{ }^{\mathrm{TM}}\right)$.

3. Half-strength potato dextrose agar (PDA; Difco $\left.{ }^{\mathrm{TM}}\right)$, supplemented with $0.75 \%$ granulated agar $\left(\mathrm{Difco}^{\mathrm{TM}}\right)$ to obtain a final concentration of $1.5 \%$ agar. 
2.2.4 Pseudomonas syringae Bioassay

\subsubsection{Pieris rapae} Two-Choice Bioassay

2.2.6 Combinatorial Hormone Application Pharmacological Assay
1. P. syringae pv. tomato DC3000 [27] or another virulent P. syringae strain (stocks stored in $25 \%$ glycerol at $-80{ }^{\circ} \mathrm{C}$ ).

2. $\mathrm{KB}$ liquid medium and $\mathrm{KB}$ agar supplemented with $25 \mathrm{mg} / \mathrm{mL}$ rifampicin to select DC3000 (see Subheading 2.2.2 and Note 2).

3. Sterilized 100-mL Erlenmeyer flasks with cotton plugs containing $25 \mathrm{~mL}$ of liquid $\mathrm{KB}$.

4. Sterilized $10 \mathrm{mM} \mathrm{MgSO}$.

5. Silwet L-77 (Van Meeuwen Chemicals, Weesp, The Netherlands).

1. First-instar (L1) larvae of P. rapae. Request the caterpillars from a collaborator or use caterpillars of your own collection (see Note 3 ).

2. Brassica oleracea (white cabbage) or Brassica campestris (Chinese cabbage) as food sources for the caterpillars.

3. Lantana sp. (shrub verbena) plants that supply nectar to the butterflies.

1. SA (Mallinckrodt Baker, Deventer, The Netherlands) or sodium salt SA (Na-SA; Sigma-Aldrich, St. Louis, MO, USA) (see Note 4).

2. Methyl jasmonate (MeJA; Brunschwig Chemie, Amsterdam, The Netherlands) ( see Note $\mathbf{5}$ ).

3. $96 \%$ Ethanol.

4. Silwet L-77 (Van Meeuwen).

5. Optionally, 1-aminocyclopropane-1-carboxylic acid (ACC; Sigma-Aldrich).

6. For plate assays with seedlings, Murashige and Skoog (MS) medium supplemented with vitamins $(\mathrm{pH}$ 5.7; Duchefa, Haarlem, The Netherlands), $5 \%$ sucrose, and plant agar $(0.85 \%$; Duchefa) in $10 \times 10 \mathrm{~cm}$ square plates.

7. For liquid assays with seedlings, MES buffer $(5 \mathrm{mM}$ 2-( $N$-morpholino)ethanesulfonic acid monohydrate (MES), $1 \mathrm{mM} \mathrm{KCl}, \mathrm{pH} 5.7$ ) in 24-well plates.

8. For seed surface sterilization: $\mathrm{HCl}(37 \%)$, household chlorine (original Glorix; Unilever, London, UK).

\section{Methods}

The introduction of microbes and insects by plant pathologists and entomologists in the plant growth facilities is harmless. The described experiments, with the exception of those with caterpillars, can be done in close proximity to other plant experiments without the risk for cross-contamination. 


\subsection{Arabidopsis Cultivation}

1. Suspend Arabidopsis seeds ( $3 \times$ more than the number of plants needed; 100 seeds weigh approximately $1.5 \mathrm{mg}$ ) in $0.1 \%$ agar in 1.5 - or $15-\mathrm{mL}$ tubes and imbibe at $4{ }^{\circ} \mathrm{C}$ for $2-4$ days (see Note 6).

2. Autoclave (moist) river sand in (double) plastic bags (with 5-10 kg sand) for $20 \mathrm{~min}$ at $121^{\circ} \mathrm{C}$.

3. Autoclave (moist) potting soil:river sand mixture (12:5) in (double) plastic bags (with $5-10 \mathrm{~kg}$ mix) for $1 \mathrm{~h}$ at $121{ }^{\circ} \mathrm{C}$. Repeat the next day.

4. Add half-strength modified Hoagland nutrient solution to the sand $(250 \mathrm{~mL} / \mathrm{kg})$ and supply water until sand is nearly saturated with fluid.

5. Fill up the $4 \mathrm{~cm}$ high small trays (100-500 mL) with the sand.

6. With a Pasteur pipette, distribute the seeds (in $0.1 \%$ agar) evenly onto the sand $\left(60\right.$ seeds $\left./ 25 \mathrm{~cm}^{2}\right)$.

7. Place the sown trays in a large tray covered with a transparent lid (to achieve $100 \%$ relative humidity) and place in a growth chamber for 12 days.

8. In a large container, mix the autoclaved soil mixture with Hoagland nutrient solution $(50 \mathrm{~mL} / \mathrm{kg})$.

9. Supply water if needed: a filled $60-\mathrm{mL}$ pot should weigh $75 \mathrm{~g}$.

10. Fill $60-\mathrm{mL}$ pots with holes in the bottom with the soil mix, push slightly on the soil top for firmness, and make one hole in the middle of the soil with the conical end of a $15-\mathrm{mL}$ tube.

11. Place the pots on small Petri dishes that function as saucers to allow individual water/nutrient supply and to prevent crosscontamination between different treatments ( see Note 7).

12. Flood the small trays containing 12-day-old seedlings in sand with water and use tweezers to gently transfer single seedlings from the sand to the planting holes in the potting soil.

13. Close the planting hole lightly by pushing the soil back around the root, leaving the above-ground plant parts free of soil.

14. Stick a color plant label in every pot for genotype/treatment indication.

15. Place the seedling-containing pots in a randomized order in large plant trays (30 plants/tray).

16. Cover the trays with transparent lids for 2 days, after which they are removed.

17. Every other day, water the plants with approximately $10 \mathrm{~mL}$ per pot during the first 10 days, and up to $20 \mathrm{~mL}$ at later growth stages.

18. Once a week, give the plants $10 \mathrm{~mL}$ of Hoagland solution (see Notes 7 and 8 ). 


\subsection{Pseudomonas fluorescens ISR Bioassay}

1. Start a culture of P. fluorescens strain WCS417 or another biocontrol pseudomonad strain by inoculating bacteria from a glycerol stock on two $\mathrm{KB}$ agar plates and incubating them for 1 day at $28^{\circ} \mathrm{C}$ ( see Note 9).

2. Harvest the bacteria by scraping them off the plates in $10 \mathrm{mM}$ $\mathrm{MgSO}_{4}$.

3. Wash the bacterial cells by spinning down in Eppendorf tubes at $1,500 \times g$ for $5 \mathrm{~min}$ in a table centrifuge and resuspend in $10 \mathrm{mM} \mathrm{MgSO}_{4}$.

4. Measure the density of the bacterial suspension in a spectrophotometer at the optical density (OD) $660 \mathrm{~nm}\left(1=10^{9}\right.$ cells $/$ $\mathrm{mL})$.

5. Mix $50 \mathrm{~mL}$ of $10^{9}$ colony-forming units $(\mathrm{cfu}) / \mathrm{mL}$ per $\mathrm{kg}$ of soil to obtain $5 \times 10^{7} \mathrm{cfu} / \mathrm{kg}$, whereas the control treatment receives $50 \mathrm{~mL}$ of $10 \mathrm{mM} \mathrm{MgSO}_{4}$ per $\mathrm{kg}$ of soil.

6. Proceed with the plant cultivation (see Subheading 3.1) and treat with pathogens/insects/hormones as described below.

1. To determine the level of disease resistance to $B$. cinerea, use 20 plants per genotype/treatment ( see Note 10).

2. For gene expression analysis, harvest ten inoculated leaves in triplicate of a total of ten plants per time point (e.g., $t=0,1$, and 2 days after inoculation) (see Note 10).

3. Start a culture of $B$. cinerea by inoculating conidia from a glycerol stock on half-strength PDA plates and incubate them for 2 weeks at $22^{\circ} \mathrm{C}$ under a 10 -h day/14-h night regime.

4. Around 1:00 p.m., harvest conidia by scraping them off the plates in half-strength PDB.

5. Filter the suspension through glass wool.

6. Measure the conidial density in a hemocytometer with a light microscope.

7. Dilute the suspension with PDB to a final concentration of $5 \times 10^{5}$ conidia/mL.

8. Leave the conidia in PDB for $2 \mathrm{~h}$ at room temperature.

9. Around 3:00 p.m., inoculate the plants by pipetting a $5-\mu \mathrm{L}$ droplet of the conidial suspension on approximately five fully grown leaves per plant ( see Note 11).

10. Place two wet towels in the plant trays and tape-shut transparent lids to the trays to create $100 \%$ relative humidity.

11. Record disease symptoms at 3-7 days after inoculation and categorize them in different disease severity classes depending on the size and appearance of the lesions (Fig. 1) (see Note 12).

12. Determine the percentage of leaves per plant falling in each disease class and by means of the Chi-square test, whether the 


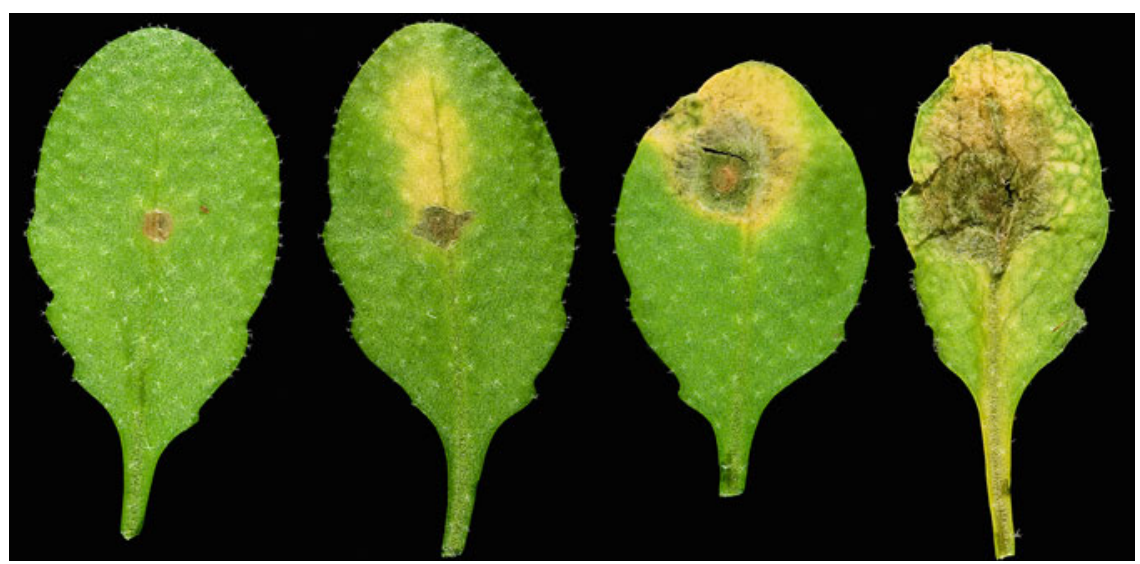

Fig. 1 Classification of disease symptoms caused by infection with $B$. cinerea. From left to right. Stage I, lesion $2 \mathrm{~mm}$; stage II, lesion $2 \mathrm{~mm}+$ chlorosis; stage III, lesion 2-4 mm + chlorosis; stage IV, lesion > $4 \mathrm{~mm}+$ chlorosis

\subsection{Pseudomonas syringae Bioassay}

distribution between the different classes differs between genotypes/treatments.

13. Determine the number of in planta-formed spores on B. cinereainfected leaves in three pools of 16 inoculated leaves of four plants per genotype/treatment.

14. Shake the leaves vigorously in a test tube containing $10 \mathrm{~mL}$ of water to release the spores from the leaf surface.

15. Use tweezers to remove the leaves, centrifuge the remaining spore suspension at $200 \times g$ for $10 \mathrm{~min}$, and resuspend the spores in $500 \mu \mathrm{L}$ of water.

16. Count the spores in a hemocytometer with a light microscope.

17. Log-transform the data and perform a Tukey's honestly significant difference test to analyze the differences between genotypes/treatments.

Basically, the resistance level against $P$. syringae can be determined by two different inoculation methods: (a) dipping and (b) pressure infiltration of the leaves with the bacterial suspension. By dipping, the bacteria enter through the stomata and start colonizing the leaves from there, whereas by infiltration the bacteria are immediately present everywhere in the apoplast of the infiltrated area. The dipping method is commonly used in ISR bioassays, whereas the infiltration method is used in most other experiments with P. syringae.

1. Use 20 plants per genotype/treatment for the dipping bioassay and 10-20 plants per treatment for the infiltration bioassay (see Notes 10 and 13). 
2. For gene expression analysis, harvest ten inoculated leaves in triplicate of a total of ten plants per time point (e.g., $t=0,6$, and $24 \mathrm{~h}$ after inoculation) ( see Note 10).

3. At around 4:00 p.m., start a culture of P. syringae by inoculating bacteria from a glycerol stock in an Erlenmeyer flask containing liquid $\mathrm{KB}$ and incubate overnight at $28{ }^{\circ} \mathrm{C}$ in an orbital shaker $(225 \mathrm{rpm})$.

4. The next morning, wash the bacterial cells by spinning them down in Eppendorf tubes at 1,500 $\times g$ for $5 \mathrm{~min}$ in a table centrifuge and resuspend them in $10 \mathrm{mM} \mathrm{MgSO}_{4}$.

5. Measure the density of the bacterial suspension in a spectrophotometer at $\mathrm{OD}_{660}\left(1=10^{9}\right.$ cells $\left./ \mathrm{mL}\right)$.

6. For the dipping bioassay, dilute the bacteria in $\mathrm{MgSO}_{4}$ until $2.5 \times 10^{7} \mathrm{cfu} / \mathrm{mL}$ and amend with Silwet L-77 to $0.02 \%(\mathrm{v} / \mathrm{v})$ to facilitate entry of the bacteria into the leaves. For the infiltration assay, dilute the bacteria to $\mathrm{OD}_{660}=0.0005$ for bioassays and to $\mathrm{OD}_{660}=0.005$ (thus tenfold higher) for gene expression analyses ( see Note 14).

7. Proceed with steps $\mathbf{8}$ and $\mathbf{1 2}$ for the dipping and infiltration assay, respectively.

8. For dipping, turn the plant in the pot upside down in the bacterial suspension, so that all the leaves are immersed, for $3 \mathrm{~s}$ (see Note 15).

9. Refresh the inoculum at least once every 30 plants and use separate boxes for differently pretreated plants to prevent cross-contamination.

10. After inoculation, place the transparent lids on the plant trays.

11. After 4 days, score the percentage of leaves with disease symptoms (presence of water-soaked lesions and chlorosis) per plant and analyze the differences between genotypes/treatments with the Tukey's honestly significant difference test.

12. For pressure infiltration, gently turn the leaf so that its adaxial side is pressed on the index finger and gently press the plunger of a needleless $1-\mathrm{mL}$ syringe firmly placed on the abaxial side to release the bacterial suspension into the leaf.

13. First, indicate with a marker pen on the petioles which leaves will be infiltrated (see Note 11).

14. After 3 days, determine the disease symptoms (see Subheading 3.4, step 11).

15. Determine the bacterial growth in planta by analyzing eight samples containing two leaf discs of two leaves of one plant, which are collected in 96-deep-well plates containing two beads per well ( see Notes 16 and 17). 


\subsection{Pieris rapae Two-Choice Bioassay}

16. After all the samples for a time point are collected, add $400 \mu \mathrm{L}$ of $10 \mathrm{mM} \mathrm{MgSO}_{4}$ to each sample with a multichannel pipette and homogenize the tissue in a plate shaker.

17. Make dilution series in 96-well dilution plates by pipetting $20 \mu \mathrm{L}$ of homogenate into $180 \mu \mathrm{L}$ of $10 \mathrm{mM} \mathrm{MgSO}_{4}$ (see Note 18).

18. Plate the serial dilutions on $\mathrm{KB}$ agar containing $25 \mathrm{mg} / \mathrm{mL}$ rifampicin to select for P. syringae pv. tomato DC3000.

19. For high-throughput plating, split the plate into two with a stripe on the back of the plate and streak $2.5-\mathrm{cm}$ lines of $10 \mu \mathrm{L}$ of a dilution of 8 samples with an 8-channel pipette (one treatment) on one half and repeat on the other half of the plate (see Note 19).

20. Incubate for 2 days at $28^{\circ} \mathrm{C}$ and count the cfu.

21 . From these data, calculate the ${ }^{10} \log$-transformed cfu $/ \mathrm{cm}^{2}$ leaf surface area and subject to the Tukey's honestly significant difference test to analyze differences between genotypes/treatments.

The caterpillars of $P$. rapae (small cabbage white butterfly) are specialists on cabbage plants and because Arabidopsis is also a member of the Cruciferaceae, they can also feed on Arabidopsis. As specialists, their performance is hardly influenced by activation of JA-dependent responses, but when given a choice, they prefer to feed on plants that express the ERF branch of the JA signaling pathway that is controlled by the ERF transcription factor ORA59 rather than be deterred by induction of the MYC branch [17]. In case of two-choice assays, the preference of the caterpillars for either one of two genotypes or treatments is tested.

1. For the two-choice bioassay, place four 6-week-old plants, two of each genotype/treatment, close together so that the leaves overlap and the caterpillars can move from one plant to the other ( see Note 20).

2. Create an empty space of at least $30 \mathrm{~cm}$ between each plant arena to prevent crossing-over of the caterpillars.

3 . To get reliable data, test the choice of the caterpillars in at least 20 arenas.

4. For gene expression analysis, plants can grow in the usual (no-choice) setup.

5. Harvest ten infested leaves in triplicate per genotype/treatment of a total of ten plants per time point (e.g., $t=0,6,24,48 \mathrm{~h}$ ).

6. Collect Ll larvae from the insect-rearing facility by cutting leaves from cabbage plants harboring caterpillars that are 1-2 days old ( see Note 21).

7. Using a fine paintbrush, place two caterpillars on each plant so that in each plant arena eight caterpillars are released. 


\subsection{Combinatorial Hormone Application Pharmacological Assay}

3.6.1 Soil-Grown Plants

3.6.2 Sterile-Grown Seedlings
8. For two-choice assays, allow the caterpillars to feed for 4 days.

9. For gene expression analyses, remove the caterpillars from the plants with a paintbrush, after $24 \mathrm{~h}$ of feeding.

10. Cut through the hypocotyl and inspect the rosette carefully to monitor the presence of the caterpillars on the different plant genotypes/treatments in each arena (see Note 22).

11. Calculate the frequency distribution of the caterpillars over the different genotypes/treatments per two-choice arena and test for statistical difference from a $50 \%$ distribution (equal choice) using the Student's $t$-test.

Preparation and application of the hormonal solutions is the same for combinatorial pharmacological assays as for hormonal induction treatments in bioassays with interacting organisms. In most of the hormone combination assays with SA and JA, we use 5-weekold soil-grown plants that are dipped in combinatorial hormonal solutions, but sterile, plate-grown or liquid medium-grown seedlings can be assayed for SA/JA cross talk as well. Usually, in hormone dipping assays, $1 \mathrm{mM} \mathrm{SA}$ and $100 \mu \mathrm{M}$ MeJA are applied to study cross-communication between hormone signaling pathways by means of their effect on gene expression $24 \mathrm{~h}$ after treatment. However, other experimental scenarios are suitable as well, because the antagonistic effect of SA on JA signaling is apparent when SA is supplied up to $30 \mathrm{~h}$ before the MeJA application and the SA/JA cross talk effects last for at least $96 \mathrm{~h}$ [19]. Moreover, SA concentrations as low as $0.1 \mu \mathrm{M}$ suffice to antagonize the JA-induced signaling.

1. To determine the effect of SA and MeJA on each other's action (such as induction of gene expression), use 30 plants per treatment in a dipping assay that allows for sampling at $t=0$ and $t=24$ h $($ see Note 10).

2. Prepare SA and MeJA solutions (see Notes 4 and 5). For dipping, add Silwet L-77 to a final concentration of $0.015 \%$ to facilitate entry into the leaves.

3. For the dipping assay, follow instructions as described in Subheading 3.4, step 8, except that lids on the trays are not fully closed, but cracked (see Notes 14 and 23).

1. Put $<200$ seeds in an open Eppendorf tube and place in a desiccator together with a $200-\mathrm{mL}$ beaker containing $97 \mathrm{~mL}$ of $\mathrm{HCl}$.

2. Add briefly $3 \mathrm{~mL}$ of chlorine to the $\mathrm{HCl}$ and mix with a pipette, immediately followed by closure of the desiccator with its lid ( see Note 24).

3. Take out the seeds after $3 \mathrm{~h}$ and transfer the seeds to MS plates. 
4. Imbibe the seeds for 2 days at $4{ }^{\circ} \mathrm{C}$, after which the sown plates are placed vertically in a growth chamber for 12 days ( see Note 25).

5. Transfer the seedlings either to fresh MS agar medium supplemented with $0.5 \mathrm{mM} \mathrm{SA}, 20 \mu \mathrm{M}$ MeJA, or a combination of both chemicals or to $1.5 \mathrm{~mL}$ of liquid MES buffer medium in 24-well plates ( 5 seedlings per well), where they are left to acclimatize for 1 day before addition of SA and MeJA at the final concentrations of $0.5 \mathrm{mM}$ and $100 \mu \mathrm{M}$, respectively (see Note 26).

\section{Notes}

1. We make $20 \times$ concentrated stock solutions and store them at room temperature. Prepare a working solution by filling a $50-\mathrm{L}$ tap can with $25 \mathrm{~L}$ tap water; add $25 \mathrm{~mL}$ of the stock solutions; fill the can up to $50 \mathrm{~L}$ with tap water. Mix solution well. To avoid algae growth, place a black bin over the can.

2. To make $1 \mathrm{~L}$ of $\mathrm{KB}$, place a 2 -L Erlenmeyer flask containing $500 \mathrm{~mL}$ demineralized water and a magnet on a magnetic stirrer. To avoid precipitation, add all the ingredients one by one and dissolve completely before adding the next compound. Adjust with water to obtain $1 \mathrm{~L}$ and pour into bottles for autoclaving. Agar has to be added to the bottle and not to the Erlenmeyer because it will not dissolve without heating.

3. Keeping an in-house colony of $P$. rapae is laborious and demands large temperature-controlled growth facilities, as one chamber is used for rearing of $P$. rapae and another to cultivate the plants needed for the rearing of $P$. rapae (see Subheading 2.2.5).

4. SA is acidic and should be buffered to neutral $\mathrm{pH}$. As at a (common) $1 \mathrm{mM}$ SA concentration, the buffering capacity of tap water suffices, we usually prepare SA solutions in tap water. Whereas Na-SA readily dissolves in water, SA does not and has to be boiled. Stock solutions of $100 \mathrm{mM}$ SA can be stored at room temperature, but boiling is required to dissolve the precipitated SA. SA (stock) solutions of a low concentration appear to lose their defense-inducing activity when stored.

5. MeJA is available as a $4.46 \mathrm{M}$ solution. Make a 1,000-fold concentrated stock in $96 \%$ ethanol by adding $10 \mu \mathrm{L}$ MeJA to $436 \mu \mathrm{L}$ ethanol, resulting in a $100 \mathrm{mM}$ MeJA solution. To all the solutions without MeJA, a similar volume of ethanol is added $(0.1 \%)$.

6. The $0.1 \%$ agar prevents the seeds from sinking to the tube bottom and allows an equal distribution of the seeds in the solution. 
7. Water and nutrients are supplied via the saucers by using a bottle dispenser fused to rubber tubing. This prevents contamination between pots and allows the fluids to stream from the bottom up and not from the top down.

8. Assays as described in this chapter can usually be performed when the plants are 5 weeks old.

9. They grow also at room temperature, albeit more slowly.

10. Plants are 5 weeks old at the time of inoculation.

11. Be careful to select leaves that are younger than leaf four, because the round-shaped older leaves tend to be very susceptible, irrespective of the genetic background or treatment of the plant.

12. The rate of disease progression and also the symptom appearance can differ between experiments and, thus, the day of symptom scoring and the criteria of the disease classes might have to be adjusted accordingly.

13. Ten plants are needed when only one time point is harvested and more plants are needed for multiple time points to determine bacterial titer.

14. Inoculation with $P$. syringae and treatment with SA preferably take place in the morning, because then SA-dependent signaling is activated stronger and the difference in disease level between resistant and susceptible plants is greater.

15. A pipette tip box can be used to contain the suspension.

16. The infiltration method is usually coupled with assessment of in planta bacterial growth, which is a highly valuable but also laborious method. Therefore, we have tried to automate it as much as possible. A one-hole puncher significantly speeds up the process of cutting leaf discs compared to the classical cork borer.

17. When samples are taken at $t=0$ to determine the number of bacteria that entered the leaves (in practice $1 \mathrm{~h}$ after inoculation), then the leaves need to be washed briefly ( $3 \mathrm{~s}$ ) in $70 \%$ ethanol and subsequently rinsed with water and dried with a tissue, before leaf discs can be sampled.

18. The $t=0$ samples are diluted $10 \times$; the $t=3$ samples are diluted $10,000 \times$, but when plants are very susceptible $1,000,000 \times$ dilutions can be needed.

19. This way, if you plate three dilutions, you use three plates per genotype/treatment.

20. Plants of the same genotype/treatment are placed diagonally to each other.

21. Seven days prior to the experiment, a fresh cabbage plant is introduced into the insect-rearing room on which butterflies are allowed to deposit eggs for 1 day, after which the plants are 
placed in a closed cage; 5 days later, the caterpillars hatch from the eggs.

22. The caterpillars are hard to track down: they are small and green and in addition, tend to crawl on the abaxial side of the leaves. Chances of finding them back increase if the rosette is held against the light, which shines through the leaves except where the caterpillars are.

23. Treat plants with hormones in the morning (before 12:00 p.m.) and sample tissue to analyze for JA-induced gene expression around 2:00 p.m., because then the plants show high sensitivity to JA while the basal expression level of genes like PDFI.2 is low. The basal PDF1.2 transcript levels are high at the end of the day due to the circadian rhythm.

24. The $\mathrm{HCl}$-chlorine mixture needs to be freshly prepared.

25. There is still chlorine gas in the seed coat after surface-sterilization and this will eventually kill the seeds if it cannot be released. Therefore, the tubes with seeds should be left open in a sterile hood for at least half an hour before they are transferred to plates or stored at $4^{\circ} \mathrm{C}$.

26. To enhance the induction of JA-sensitive genes that are coregulated by ethylene, like those under control of the ERF branch of the JA signaling pathway, $0.002 \mathrm{mM}$ ACC can be added to the medium. Be careful with increasing the ethylene concentration in the assay, because it is known to suppress the antagonism by SA on JA signaling [20].

\section{Acknowledgments}

The authors would like to thank other (previous) members of the laboratory who have contributed to developing the foregoing protocols. The authors are supported by the Netherlands Organization of Scientific Research (VICI grant no. 865.04.002 and VIDI grant no. 11281) and a European Research Council Advanced Grant (no. 269072).

\section{References}

1. Chester KS (1933) The problem of acquired physiological immunity in plants. Q Rev Biol $8: 129-154$

2. Chester KS (1933) The problem of acquired physiological immunity in plants (Continued). Q Rev Biol 8:275-324

3. Pieterse CMJ, Van der Does D, Zamioudis C, Leon-Reyes A, Van Wees SCM (2012) Hormonal modulation of plant immunity. Annu Rev Cell Dev Biol 28:489-521. doi: 101146/annurev-cellbio-092910-154055
4. Howe GA, Jander G (2008) Plant immunity to insect herbivores. Annu Rev Plant Biol 59:41-66

5. Glazebrook J (2005) Contrasting mechanisms of defense against biotrophic and necrotrophic pathogens. Annu Rev Phytopathol 43: 205-227

6. Van Wees SCM, Van der Ent S, Pieterse CMJ (2008) Plant immune responses triggered by beneficial microbes. Curr Opin Plant Biol $11: 443-448$ 
7. Van Loon LC, Bakker PAHM, Pieterse CMJ (1998) Systemic resistance induced by rhizosphere bacteria. Annu Rev Phytopathol 36: $453-483$

8. Van der Ent S, Van Wees SCM, Pieterse CMJ (2009) Jasmonate signaling in plant interactions with resistance-inducing beneficial microbes. Phytochemistry 70:1581-1588

9. Zamioudis C, Pieterse CMJ (2012) Modulation of host immunity by beneficial microbes. Mol Plant-Microbe Interact 25:139-150

10. De Vos M, Van Oosten VR, Van Poecke RMP, Van Pelt JA, Pozo MJ, Mueller MJ, Buchala AJ, Métraux J-P, Van Loon LC, Dicke M, Pieterse CMJ (2005) Signal signature and transcriptome changes of Arabidopsis during pathogen and insect attack. Mol Plant-Microbe Interact 18:923-937

11. Pieterse CMJ, Leon-Reyes A, Van der Ent S, Van Wees SCM (2009) Networking by smallmolecule hormones in plant immunity. Nat Chem Biol 5:308-316

12. Van Wees SCM, Luijendijk M, Smoorenburg I, Van Loon LC, Pieterse CMJ (1999) Rhizobacteria-mediated induced systemic resistance (ISR) in Arabidopsis is not associated with a direct effect on expression of known defense-related genes but stimulates the expression of the jasmonate-inducible gene Atvsp upon challenge. Plant Mol Biol 41: 537-549

13. Spoel SH, Koornneef A, Claessens SMC, Korzelius JP, Van Pelt JA, Mueller MJ, Buchala AJ, Métraux J-P, Brown R, Kazan K, Van Loon LC, Dong X, Pieterse CMJ (2003) NPRl modulates cross-talk between salicylate- and jasmonate-dependent defense pathways through a novel function in the cytosol. Plant Cell 15:760-770

14. Anderson JP, Badruzsaufari E, Schenk PM, Manners JM, Desmond OJ, Ehlert C, Maclean DJ, Ebert PR, Kazan K (2004) Antagonistic interaction between abscisic acid and jasmonateethylene signaling pathways modulates defense gene expression and disease resistance in Arabidopsis. Plant Cell 16:3460-3479

15. Penninckx IAMA, Thomma BPHJ, Buchala A, Métraux J-P, Broekaert WF (1998) Concomitant activation of jasmonate and ethylene response pathways is required for induction of a plant defensin gene in Arabidopsis. Plant Cell 10:2103-2113

16. Bodenhausen N, Reymond P (2007) Signaling pathways controlling induced resistance to insect herbivores in Arabidopsis. Mol PlantMicrobe Interact 20:1406-1420

17. Verhage A, Vlaardingerbroek I, Raaymakers C, Van Dam NM, Dicke M, Van Wees SCM, Pieterse CMJ (2011) Rewiring of the jasmonate signaling pathway in Arabidopsis during insect herbivory. Front Plant Sci 2:47

18. Robert-Seilaniantz A, Grant M, Jones JDG (2011) Hormone crosstalk in plant disease and defense: more than just jasmonate-salicylate antagonism. Annu Rev Phytopathol 49: 317-343

19. Koornneef A, Leon-Reyes A, Ritsema T, Verhage A, Den Otter FC, Van Loon LC, Pieterse CMJ (2008) Kinetics of salicylatemediated suppression of jasmonate signaling reveal a role for redox modulation. Plant Physiol 147:1358-1368

20. Leon-Reyes A, Du Y, Koornneef A, Proietti S, Körbes AP, Memelink J, Pieterse CMJ, Ritsema $\mathrm{T}$ (2010) Ethylene signaling renders the jasmonate response of Arabidopsis insensitive to future suppression by salicylic acid. Mol PlantMicrobe Interact 23:187-197

21. Leon-Reyes A, Spoel SH, De Lange ES, Abe $\mathrm{H}$, Kobayashi M, Tsuda S, Millenaar FF, Welschen RAM, Ritsema T, Pieterse CMJ (2009) Ethylene modulates the role of nonexpressor of pathogenesis-related genesl in cross talk between salicylate and jasmonate signaling. Plant Physiol 149:1797-1809

22. Leon-Reyes A, Van der Does D, De Lange ES, Delker C, Wasternack C, Van Wees SCM, Ritsema T, Pieterse CMJ (2010) Salicylatemediated suppression of jasmonate-responsive gene expression in Arabidopsis is targeted downstream of the jasmonate biosynthesis pathway. Planta 232:1423-1432

23. Lorenzo O, Chico JM, Sánchez-Serrano JJ, Solano R (2004) Jasmonate-insensitive l encodes a MYC transcription factor essential to discriminate between different jasmonate-regulated defense responses in Arabidopsis. Plant Cell 16:1938-1950

24. Hoagland DR, Arnon DI (1938) The waterculture method for growing plants without soil. Calif Agric Exp Stn Circ 347:1-39

25. Lamers JG, Schippers B, Geels FP (1988) Soilborne diseases of wheat in the Netherlands and results of seed bacterization with pseudomonads against Gaeumannomyces graminis var. tritici. In: Jorna ML, Slootmaker LAJ (eds) Cereal breeding related to integrated cereal production. Pudoc, Wageningen, The Netherlands, pp 134-139

26. King EO, Ward MK, Raney DE (1954) Two simple media for the demonstration of pyocyanin and fluorescin. J Lab Clin Med 44: 301-307

27. Whalen MC, Innes RW, Bent AF, Staskawicz BJ (1991) Identification of Pseudomonas syringae pathogens of Arabidopsis and a bacterial locus determining avirulence on both Arabidopsis and soybean. Plant Cell 3:49-59 